SHORT REPORT

\title{
Strategies for prevention of soccer related injuries: a systematic review
}

\author{
L Olsen, A Scanlan, M MacKay, S Babul, D Reid, M Clark, P Raina
}

Br J Sports Med 2004;38:89-94. doi: 10.1136/bjsm.2002.003079

\begin{abstract}
Objectives: To examine evidence on the effectiveness of current injury prevention strategies in soccer, determine the applicability of the evidence to children and youth, and make recommendations on policy, programming, and future research.

Methods: Standard systematic review methodology was modified and adopted for this review. Research questions and relevance criteria were developed a priori. Potentially relevant studies were located through electronic and hand searches. Articles were assessed for relevance and quality by two independent assessors, and the results of relevant articles were abstracted and synthesised.

Results: A total of 44 potentially relevant articles from electronic ( $n=37$ ) and hand $(n=7)$ searches yielded four that met inclusion criteria. These four studies addressed a range of intervention strategies and varied with respect to results and quality of evidence.

Conclusions: Some of the strategies look promising but lack adequate evaluation or require further research among younger players. Practice, policy, and research recommendations are provided as a result of the synthesis.
\end{abstract}

l nterest in soccer has increased considerably over the last decade. Soccer is the most popular sport in the world, with about 200 million participants including both sexes and across all age groups. ${ }^{1}$ For example, participation rates reported by the Canadian Soccer Association increased by about $10 \%$ a year between 1995 and 2000. With the increasing popularity of the sport, it is likely that the number of injuries has also increased. ${ }^{3}$ The numbers of soccer injuries reported in the Canadian Hospitals Injury Reporting and Prevention Program, which records emergency department visits in 15 hospitals across the country, has shown an increase in the number of cases of soccer injuries in 5-14 year old children. For example, between 1997 and 2001, among 59 year olds, the number of cases of soccer injuries in the database rose from 32 to 64 per 10000 cases of all types(Health Canada, personal communication, December 2002. Canadian Hospitals Injury Reporting and Prevention Program). Although these do not reflect population based rates, the increased number of cases may reflect more injuries as soccer participation rises across Canada.

With further growth of the sport and related injuries anticipated, it appeared timely to examine research evidence on the safety practices that best limit injuries in young players. As this literature had not previously been synthesised, an approach based on the principles of evidence based medicine was selected as it allows an unbiased and systematic identification and synthesis of valid scientific data. ${ }^{4}$ These best evidence data may then be used for clinical decision making as well as formulating strategies for effective interventions to prevent injuries in a target population. A systematic review is a review in which there is a comprehensive search for relevant studies on a specific topic, and those identified are then appraised and synthesised according to a predetermined and explicit method. 5

The aim of this review was to (a) examine evidence on the effectiveness of current injury prevention strategies in soccer, (b) determine the applicability of the evidence to children and youth, and (c) make recommendations on policy, programming, and future research.

\section{METHODS}

This review, which is part of a larger report on sport and recreational activities, used standard systematic review methods including explicit and reproducible procedures for systematically identifying and selecting studies, grading the strength of evidence, and extracting information. However, adaptations to these methods were made in consultation with an expert panel of professionals in the field to suit the particular needs of this project. Additional details on the methodology are described elsewhere. ${ }^{6}$

A set of relevance criteria was developed a priori. The criteria required that to be included, a document needed to:

- address unintentional injury prevention;

- evaluate the effectiveness of (a) an educational injury prevention programme/strategy, (b) a policy/regulation/ legislative change, $(c)$ a community organisation effort, $(d)$ environmental, equipment, or product modifications;

- contain as an outcome (a) injury incidence (excluding reinjury), (b) injury severity, (c) uptake of risk reducing behaviours, $(d)$ uptake or compliance with injury prevention measures;

- contain a control group in its methodological design or use other comparative measures.

A search filter and electronic search strategy were developed in collaboration with a librarian with extensive experience in conducting systematic reviews. The search filter used a series of soccer related keywords to extract potentially relevant articles from nine electronic databases: Medline, Psychinfo, CINAHL, Current Contents, HealthSTAR, Sportdiscus, the Cochrane Database for Systematic and Complete Reviews, the Cochrane Controlled Trials Registry, and EMBASE (table 1).

All databases were searched for all languages and age groups and from the earliest records available. Duplicates between databases were identified and removed to create a master list.

Abbreviations: $A C L$, anterior cruciate ligament; $R C T$, randomised controlled trial 
Table 1 Soccer electronic search strategy

\begin{tabular}{|c|c|}
\hline Sport terms & Injury prevention terms \\
\hline $\begin{array}{l}\text { football/ } \\
\text { rugby/ } \\
\text { (soccer or football } \$ \text { or foot } \\
\text { ball } \$ \text { or rugby).tw. }\end{array}$ & $\begin{array}{l}1 \text { Accident prevention } \\
2 \text { exp injury/pc } \\
3 \text { exp safety } \\
4 \text { safety.tw. } \\
5 \text { or } / 1-4 \\
6 \text { (prevent } \$ \text { or risks } \$ \text { ).tw. or pc.fs. } \\
7 \text { (injur } \$ \text { or accident } \$ \text { ) or trauma } \$ \text {.tw. } \\
8 \text { exp accidents and accident related } \\
\text { phenomena } \\
9 \text { sport injury } \\
10 \text { (sprain } \$ \text { or strain } \$ \text { ).tw. } \\
11 \text { exp sprain } \\
12 \text { or } / 7-11 \\
136 \text { and } 12 \\
145 \text { or } 13\end{array}$ \\
\hline
\end{tabular}

One member of the research team screened each citation in the master list, including the abstract when available, to assess whether it pertained to unintentional injury and involved the evaluation of an injury prevention strategy or if not specifically stated, provided an indication that it might involve one. If no abstract was available, information was taken from the article title. Articles that met these broad criteria were obtained for relevance assessment. Additional sources were also hand searched to identify studies not captured in the electronic searches. Sources for hand searching included the reference lists of all articles deemed relevant, all review articles identified by the electronic search and sport injury textbooks published after 1990 for soccer, a report published by the Monash University Accident Research Centre in Australia, ${ }^{7}$ and the table of contents from the American Journal of Sports Medicine. The American Journal of Sports Medicine was selected for hand searching as it was the only journal that met the predetermined criteria of being the source for at least $10 \%$ of the relevant articles. Hard copies were obtained from university libraries in Ottawa or Vancouver or through the Canadian Institute for Scientific and Technical Information. Articles not available through any of these sources were ordered through interlibrary loan services. Articles that arrived before the start of write up of the final report were included in the review.

A form was developed to assess study relevance using six main criteria: relevance of research topic, specific sport and recreation area, evaluation of injury prevention strategy, outcome measures related to injury or behavioural measures, and methods used-that is, whether the study design included a control group or another comparative measure. One refinement was made to the relevance criteria early in the process. Studies that had biomechanical measures as an outcome related to injury-for example, torque, resistance, or absorption-were excluded, as these outcomes had not been specifically addressed in the search strategy. Two team members independently reviewed all English and French language articles identified as potentially relevant. Any disagreement between paired reviewers was resolved by discussion, and, when necessary, a third reviewer made the final decision. For foreign language articles other than French, assessment of relevance was attempted if an English title and abstract were available. If an article appeared to be relevant, one reviewer proficient in the foreign language was located and the article was reviewed for relevance and abstracted.

Two reviewers independently extracted data to allow synthesis of findings and an assessment of quality. Data on year of publication, country of origin, description of type of activity (for example, competitive versus non-competitive), study purpose, design, setting, time period, and sample size, population(s) studied, intervention, primary outcome(s), and key results were abstracted using a standardised tool. If the primary outcome was unclear, the most serious outcome reported was selected.

Quality of randomised controlled trials (RCTs) was evaluated using the quality assessment tool validated by Jadad et al. ${ }^{8}$ As no validated tools existed to assess the quality of reporting for the remaining study designs, specific quality assessment forms were developed for: case control, cohort, non-equivalent control group, and pre-test post-test/time series studies. Quality assessment form development included an extensive Medline search, which resulted in 18 instruments from which a series of questions was developed. These addressed quality of reporting (for example, study aims, main outcomes, inclusion/exclusion criteria described), internal validity (for example, confounding, selection and assessment bias, as well as intervention integrity), and external validity (for example, representativeness) of study designs other than RCTs. Some questions were applied to all study designs, whereas others were specific to a particular design. The resulting series of questions was reviewed by an international multidisciplinary panel of design and methodology experts. On the basis of their recommendations, a form for each study design was developed and pilot tested.

Quality scores, representing subscores for quality of reporting and internal validity, were summed to calculate an overall score that reflected a rating of each study according to criteria specific to study design. Design specific overall scores were converted into percentage value and rated as poor $(0-49 \%)$, moderate $(50-89 \%)$, or good $(90-100 \%)$ to allow a direct comparison across study designs.

\section{RESULTS}

The electronic search identified 37 potentially relevant soccer related articles. Seven additional articles were identified through hand searching. Of the 44 potentially relevant articles identified, only five met the relevance criteria (table 2). As two of these studies reported on the same research data, the more recent of the two publications was selected for data abstraction, leaving a total of four relevant studies.

As two of these studies reported on the same research data, the more recent of the two publications was selected for data abstraction. ${ }^{9}{ }^{10}$ The most commonly cited reason for exclusion was that the study did not evaluate the effectiveness of an injury prevention intervention as specified in the relevance criteria (table 3 ).

Of the relevant articles, two of the four were conducted in the United States, the others in Sweden and Italy. One was an RCT, two were time series, and one was a non-equivalent control group design. All addressed organised, competitive soccer, but covered a range of intervention strategies and varied in the strength of evidence they provided. Two of the articles assessed the effectiveness of training programmes to specifically reduce knee injuries. The first of these, an RCT by Ekstrand and Gillquist, ${ }^{10}$ assessed the effectiveness of a seven part programme to reduce injury incidence in 17-36 year old male players in a Swedish community soccer league. Coaches selected the 15 best players from each of 12 teams, who were then randomly assigned to one of six intervention teams ( $\mathrm{n}$ $=90$ players $)$ or to one of six control teams $(n=90$ players $)$. Intervention teams were then enrolled in a seven part programme, delivered by doctors and physiotherapists, consisting of:

- correction of training consisting of a specific warm up and cool down programme 
Table 2 Summary of soccer studies including design, intervention, and results

\begin{tabular}{|c|c|c|c|c|c|c|c|c|}
\hline $\begin{array}{l}\text { First } \\
\text { author }\end{array}$ & $\begin{array}{l}\text { Study } \\
\text { design }\end{array}$ & $\begin{array}{l}\text { Quality } \\
\text { rating }\end{array}$ & Study aim & Study setting & $\begin{array}{l}\text { Study participants/ } \\
\text { targets }\end{array}$ & Intervention type & $\begin{array}{l}\text { Primary } \\
\text { outcome } \\
\text { measure }\end{array}$ & Conclusion \\
\hline Ekstand & RCT & Poor $(2 / 5)$ & $\begin{array}{l}\text { Test a multicompo- } \\
\text { nent prophylactic } \\
\text { training programme } \\
\text { delivered by (1) } \\
\text { trainers and } \\
\text { physiotherapists and } \\
\text { (2) coaches }\end{array}$ & $\begin{array}{l}\text { Community } \\
\text { soccer league }\end{array}$ & $\begin{array}{l}180 \text { male players } \\
\text { aged } 17-36 \text { years } \\
\text { participating in } 12 \\
\text { teams from a } \\
\text { Swedish community } \\
\text { soccer league; } 15 \\
\text { best players per } \\
\text { team selected }\end{array}$ & $\begin{array}{l}\text { Education: special } \\
\text { warm up/ } \\
\text { cool down training; } \\
\text { information to } \\
\text { coaches and } \\
\text { players; correction } \\
\text { and supervision of } \\
\text { training. } \\
\text { Environmental: leg } \\
\text { guards, ankle taping }\end{array}$ & $\begin{array}{l}\text { Injury } \\
\text { incidence \& } \\
\text { absence from } \\
\text { games and } \\
\text { practices } \\
9\end{array}$ & $\begin{array}{l}\text { After a six-month } \\
\text { follow up, there were } \\
75 \% \text { fewer injuries in } \\
\text { the intervention } \\
\text { teams. There were } \\
\text { also lower levels of } \\
\text { ankle, knee strains, } \\
\text { sprains, operations, } \\
\text { and absence from } \\
\text { games among the } \\
\text { intervention teams. } \\
\text { Additional follow up } \\
\text { that did not adhere } \\
\text { to the randomisation } \\
\text { showed a lesser } \\
\text { degree of injury } \\
\text { reduction when } \\
\text { coaches delivered } \\
\text { the intervention }\end{array}$ \\
\hline Caraffa & $\begin{array}{l}\text { Non- } \\
\text { equivalent } \\
\text { control } \\
\text { group }\end{array}$ & $\begin{array}{l}\text { Moderate } \\
(10 / 14)\end{array}$ & $\begin{array}{l}\text { Assess the ability } \\
\text { of a propriocep- } \\
\text { tive training } \\
\text { programme to } \\
\text { reduce the } \\
\text { incidence of } \mathrm{ACL} \\
\text { injuries }\end{array}$ & $\begin{array}{l}\text { Community } \\
\text { sport club/40 } \\
\text { semi- } \\
\text { professional } \\
\text { and amateur } \\
\text { teams }\end{array}$ & $\begin{array}{l}40 \text { teams of male } \\
\text { professional and } \\
\text { amateur soccer } \\
\text { players in Italy (age } \\
\text { not reported) }\end{array}$ & $\begin{array}{l}\text { Education: pre- } \\
\text { season, } 5 \text {-phase } \\
\text { training programme } \\
\text { of increasing } \\
\text { difficulty. At least } \\
20 \text { min a day for a } \\
\text { min. of } 30 \text { days }\end{array}$ & $\begin{array}{l}\text { Incidence of } \\
\mathrm{ACL} \text { injuries }\end{array}$ & $\begin{array}{l}\text { The frequency of } \\
\mathrm{ACL} \text { injuries in the } \\
\text { proprioceptive- } \\
\text { trained group } \\
\text { showed a sevenfold } \\
\text { reduction over the } \\
\text { control group }\end{array}$ \\
\hline Elias & Time series & $\begin{array}{l}\text { Moderate } \\
(8 / 15)\end{array}$ & $\begin{array}{l}\text { Assess the effects of } \\
\text { emergency } \\
\text { preventive measures } \\
\text { to prevent heat } \\
\text { exhaustion }\end{array}$ & $\begin{array}{l}\text { Summer youth } \\
\text { soccer } \\
\text { tournament }\end{array}$ & $\begin{array}{l}4000 \text { male and } \\
\text { female players aged } \\
9-19 \text { years exposed } \\
\text { to preventive } \\
\text { measures at } \\
\text { tournament }\end{array}$ & $\begin{array}{l}\text { Regulatory: game } \\
\text { modifications: } \\
\text { shorter game times, } \\
\text { longer breaks, } \\
\text { unlimited } \\
\text { substitutions. } \\
\text { Environmental: } \\
\text { spraying players } \\
\text { with water }\end{array}$ & $\begin{array}{l}\text { Incidence of } \\
\text { heat } \\
\text { exhaustion }\end{array}$ & $\begin{array}{l}\text { Rate of heat } \\
\text { exhaustion per } 1000 \\
\text { player hours } \\
\text { decreased after } \\
\text { implementation of } \\
\text { emergency measures }\end{array}$ \\
\hline Lehnhard & Time series & $\begin{array}{l}\text { Moderate } \\
(7 / 14)\end{array}$ & $\begin{array}{l}\text { Determine whether } \\
\text { strength training had } \\
\text { an effect on the } \\
\text { incidence of injuries }\end{array}$ & $\begin{array}{l}\text { College soccer } \\
\text { team }\end{array}$ & $\begin{array}{l}\text { A team of college } \\
\text { level male soccer } \\
\text { players in the } \\
\text { United States } \\
\text { (age not reported) }\end{array}$ & $\begin{array}{l}\text { Education: twice } \\
\text { weekly strength } \\
\text { training sessions } \\
\text { during the non- } \\
\text { season and the } \\
\text { preseason }\end{array}$ & $\begin{array}{l}\text { Incidence of } \\
\text { injuries (team } \\
\text { injury rates) }\end{array}$ & $\begin{array}{l}\text { Reduction in team } \\
\text { injury rates }\end{array}$ \\
\hline
\end{tabular}

- equipment consisting of compulsory leg guards and training shoes

- prophylactic ankle taping for those with previous ankle sprains and/or instability

- controlled rehabilitation for lower extremity injuries

- exclusion of players with knee instability

- information to coaches and players on disciplined play and injury risks

- correction and supervision of prophylactic measures by doctors and physiotherapists

After a six month follow up, the intervention teams had $75 \%$ fewer injuries than the control teams ( 0.6 injuries per month $v 2.6$ injuries per month respectively, $\mathrm{p}<0.001)$. In this study, injuries were defined as minor (absent from practice for less than one week), moderate (absent from practice for more than one week but less than one month), or major (absent for more than one month). Reductions in the incidence of ankle injuries, sprains, strains, operations, and absences from practices and games were also reported for the intervention teams. Additional follow up data were collected and analysed in the second phase of the study where the intervention was delivered by coaches. However, this analysis did not adhere to the randomised controlled study design as it compared the injury rates before and after intervention for all teams combined. The second study phase showed a smaller reduction in injuries than the first phase (50\%). Overall, this study showed the effectiveness of a multicomponent programme. However, it is not possible to assess the relative contributions of the different programme components. The study rated poor on Jadad's RCT quality assessment scale $(2 / 5)$ (table 4$)$.

The second study was a non-equivalent control group design by Caraffa et al, ${ }^{11}$ which tested the ability of a proprioceptive training programme to reduce the incidence of anterior cruciate ligament (ACL) injury in semiprofessional and amateur male soccer players in Italy. ${ }^{11} \mathrm{~A}$ total of 40 teams participated, with half following a five phase preseason training programme using wobble boards at least three times a week during the season, while the other teams received no special training. All teams were followed for three seasons, and the incidence of ACL injuries in teams that followed the programme was 0.15 per team per season compared with 1.15 per team per season in the control teams $(p<0.001)$. The authors concluded that the programme led to a sevenfold decrease in ACL injuries. This study was rated as moderate $(10 / 14)$ in the quality assessment score (using the nonequivalent control group design quality assessment form) (table 4).

Lehnhard et al ${ }^{12}$ conducted a time series study in the United States over a four year period to assess the effectiveness of a strength training programme on the incidence of injuries in male college soccer team players. The team was monitored for 
Table 3 Reasons for exclusion of non-relevant soccer articles

\begin{tabular}{lll}
\hline $\begin{array}{l}\text { Reasons for exclusion of non-relevant } \\
\text { soccer articles }\end{array}$ & $\begin{array}{l}\text { No from } \\
\text { computer } \\
\text { searching }\end{array}$ & $\begin{array}{l}\text { No from hand } \\
\text { searching }\end{array}$ \\
\hline Potentially relevant articles & 37 & 7 \\
Relevant articles & 4 & 1 \\
Non-relevant articles & 33 & 6 \\
Research topic not addressed & 4 & \\
Different sport/recreation area & 3 & 1 \\
Intervention type criteria not met & 14 & 1 \\
Outcome measure criteria not met & 4 & \\
Methods-no comparative measures & 2 & \\
Biomechanical studies & 5 & 3 \\
Other reason (duplicate) & 1 & 1 \\
\hline
\end{tabular}

four years with a strength training regimen incorporated into the non-season and preseason during the third and fourth years. In the strength training programme, upper and lower body muscles were exercised separately twice a week. The injury rate during the years without the strength training was 15.15 per 1000 exposures compared with 7.99 per 1000 exposures for the two years with the strength training. The authors acknowledge the potential confounding effect of the study design and concluded that the reduction in injuries cannot be attributed to the strength training programme with any certainty. This study was rated as moderate (7/14) using the pre-test post-test/time series design quality assessment form (table 4).

The final study, a comprehensive or multicomponent approach to reducing heat stroke during a tournament, was conducted in the United States during a six day youth soccer tournament involving 4000 male and female players aged 919 years. ${ }^{13} \mathrm{~A}$ time series design was used to assess the effects of emergency preventive measures to prevent heat exhaustion during the tournament, which took place in July 1988. The intervention included provision of heat stroke prevention information to staff, coaches, officials, and referees, as well as emergency measures with game modifications and hydration techniques. The educational strategies were implemented before the start of the tournament, and the game modifications and hydration techniques began on the third day of the tournament. The rate of heat exhaustion per 1000 player hours decreased after implementation of the emergency measures from 21 cases in the first two days to 13 cases in the last four days. Unfortunately, the results were presented graphically and did not include numerical values or any measures of statistical significance. The authors acknowledged that the limited number of cases prohibited statistical analysis; however, they suggested that the heat related illness prevention measures were effective and probably not accounted for by heat acclimation, which generally takes a longer period of time. They suggested guidelines for youth sports organisations that recommend different preventive measures and incorporate wet bulb glove temperatures as an indicator of risk for heat stress. This study received a moderate rating of $8 / 15$ using the pre-test post-test/time series design quality assessment form (table 4).

\section{DISCUSSION}

The proprioceptive training programme evaluation by Caraffa et $a l^{11}$ provides good evidence of reductions in ACL injuries in male players at a senior level. However, as this evidence is from only one study, it would appear that further testing of this intervention is necessary, particularly to assess its effectiveness in younger players. The strength training protocol of Lehnhard et al ${ }^{12}$ also showed potential benefit.
However, as this study did not use a control group, it is difficult to attribute the observed changes to the protocol with any certainty. It may be helpful to look at other sports where the effect of strength training has been evaluated and assess whether it has been adequately evaluated in younger players. Multicomponent approaches to soccer injury prevention may also hold promise, as indicated by the results from Ekstrand and Gillquist. ${ }^{10}$ Again evidence is based on a single study, and the ideal configuration for such a programme among younger players is unknown and would need to be assessed and tested, ideally with a multifactorial design that evaluated the individual impact of each of the individual strategies. Finally, the environmental heat injury prevention study showed a trend of fewer heat related injuries during a large tournament in which a set of emergency measures were implemented. ${ }^{13}$ Owing to major limitations of this study, it is not possible to draw conclusions on the effectiveness of these measures. However, as heat stroke and heat exhaustion are potentially lethal outcomes, further exploration of this issue, particularly in younger players, would be useful.

As pointed out by Larson et al, ${ }^{3}$ evaluation of injury prevention measures in youth soccer has been all but ignored. Of the four studies assessed in this review, only one was conducted in players under the age of 17, and only one included female participants. In youth soccer, girls may be at increased risk of injury for similar levels of exposure, ${ }^{14}$ emphasising the need for surveillance and greater attention to evaluation of effective injury prevention strategies in this population.

The four studies reviewed in this paper examine different intervention approaches, and, although definitive conclusions cannot be drawn, suggestions for future research can be made. Further, it is important to note the absence of studies of a number of current preventive practices. The paucity of research should not be taken as a sign that there is little that can be done to prevent soccer injuries, but rather that most injury prevention strategies currently used in soccer do not appear to have been evaluated, particularly with respect to their use in younger players.

\section{Recommendations for future research \\ Soccer injury surveillance}

Assessing the best injury prevention strategies for soccer requires a complete understanding of the factors that contribute to both the occurrence of these injuries and the uptake of, or compliance with, potential prevention strategies. One of the challenges currently facing those interested in preventing soccer injuries is the lack of good surveillance data to allow the identification of these factors and the use of that information in developing and evaluating prevention strategies and/or policies. Prevention strategies can take the form of education and awareness raising activities (for example, skill building sessions), engineering modifications (for example, new equipment designs), or setting and enforcement of policy (for example, rules of competition). Strategies can be targeted at the sports participant (host), a potential hazard (agent of injury), or the surrounding environment. However, to gain a more complete picture of how soccer injuries affect young players, a more complete assessment of the patterns of injury is needed. This could be accomplished through the establishment of targeted surveillance and data collection strategies involving both organised and non-organised settings.

\section{Player behaviour and training}

The research reviewed in this study has provided modest evidence on the effectiveness of training programmes to reduce injuries in adults. However, little is known about the impact of similar programmes on younger players. Future 


\begin{tabular}{|c|c|c|c|c|}
\hline First author & Design & Quality rating subscores & & Main limitation \\
\hline Ekstrand & RCT & $\begin{array}{l}\text { Randomisation } \\
\text { Double blind } \\
\text { Drop outs described } \\
\text { Total }\end{array}$ & $\begin{array}{l}1 / 2 \\
0 / 2 \\
1 / 1 \\
2 / 5\end{array}$ & $\begin{array}{l}\text { Lack of adherence to origina } \\
\text { RCT design }\end{array}$ \\
\hline Caraffa & $\begin{array}{l}\text { Non-equivalent } \\
\text { control group }\end{array}$ & $\begin{array}{l}\text { Reporting } \\
\text { Internal validity } \\
\text { Total } \\
\text { Percentage }\end{array}$ & $\begin{array}{l}5 / 6 \\
5 / 8 \\
10 / 14 \\
71 \%\end{array}$ & Comparability of groups \\
\hline Elias & $\begin{array}{l}\text { Time series } \\
\text { (Pre-post) }\end{array}$ & $\begin{array}{l}\text { Reporting } \\
\text { Internal validity } \\
\text { Total } \\
\text { Percentage }\end{array}$ & $\begin{array}{l}3 / 6 \\
5 / 9 \\
8 / 15 \\
53 \%\end{array}$ & $\begin{array}{l}\text { Limitations in design and } \\
\text { reporting }\end{array}$ \\
\hline $\begin{array}{l}\text { Lehnhard } \\
\text { (Pre-post 2)* }\end{array}$ & Time series & $\begin{array}{l}\text { Reporting } \\
\text { Internal validity } \\
\text { Total } \\
\text { Percentage }\end{array}$ & $\begin{array}{l}3 / 5 \\
4 / 9 \\
7 / 14 \\
50 \%\end{array}$ & Comparability of groups \\
\hline
\end{tabular}

research studies should assess how well proprioceptive training programmes work to prevent soccer injuries in younger players of both sexes. In addition, research is needed to assess how strength training and conditioning can best be adapted to suit younger players, and how effective such adapted programmes are in preventing injuries among youth. Multicomponent injury prevention programmes involving two or more warm up, cool down, stretching, and strength training sessions in young players may also prove beneficial. However, further study is required to better understand the optimal design of such programmes. The effectiveness of standard equipment used in soccer at all levels, such as shin guards, requires further evaluation. Other preventive practices such as ankle taping and bracing also require further evaluation.

Finally, given that soccer participation has been found to be associated with mild cognitive impairment, ${ }^{15}$ further research is needed to (a) verify exposure levels to heading across different age groups, (b) assess exposure and injury at different levels of play, and (c) determine the optimum age for teaching safe heading skills. ${ }^{16}$ Finally, given that the American Academy of Pediatrics ${ }^{17}$ have suggested that protective eyewear and mouth guards may be helpful in reducing non-fatal head and facial injuries in soccer players, further evaluation of the effectiveness of these strategies is needed.

\section{Environment and facilities}

Prevention of heat illness is an important issue for young soccer players, and research is needed to assess how heat related injuries can best be avoided in this age group. Research efforts are also needed to address environmental factors such as goal post padding and anchoring as well as suitability of playing surfaces for younger players to maximise safe play. Further rule modifications to tackle violence and aggressive rule infractions-for example, automatic red card for tackling from behind-and their enforcement require evaluation.

\section{Conclusion}

Effective injury prevention strategies based on sound surveillance data and high quality research are essential for fostering safety and preventing injuries in soccer players. This review set out to identify research that evaluated injury prevention interventions aimed at young soccer players and found a serious lack of research in this area, with only one study that specifically addressed youth. This lack of research is surprising considering the enormous and increasing popularity of youth soccer around the world. The lack also raises concerns about injury prevention strategies that are currently in use. Without adequate research we cannot know which practices are effective at reducing the risk of soccer injuries. Thus, although we were not able to generate specific practice recommendations aimed at youth soccer players, the gaps identified and the research reviewed do provide guidance for furthering research efforts and tailoring studies to injury issues specific to younger players.

\section{Authors' affiliations}

L Olsen, A Scanlan, S Babul, M Clark, University of British Columbia, Vancouver, Canada

M MacKay, D Reid, Plan-it-Safe, Children's Hospital of Eastern Ontario, Canada

P Raina, Evidence-Based Practice Center, Department of Clinical Epidemiology \& Biostatistics, McMaster University, Hamilton, Ontario, Canada

Correspondence to: L Olsen, University of British Columbia, BC Injury Research and Prevention Unit, L408, 4480 Oak Street, Vancouver V7L 2B3, Canada; lolsen@cw.bc.ca

Accepted 18 February 2003

\section{REFERENCES}

1 Patel DR, Stier B, Luckstead EF. Major international sport profiles. Pediatr Clin North Am 2002:49:769-92.

2 Canadian Soccer Association. www.canadasoccer.com/eng/about/ index.asp.

3 Larson M, Pearl AJ, Jaffet R, et al. Soccer. In: Caine DJ, Caine CG, Lindner KJ, eds. Epidemiology of sports injuries. Champaign, IL: Human Kinetics Publishers, 1996:387-99.

4 Walder B, Tramer MR. Evidence-based medicine and the systematic review in perioperative medicine. Anesthetist 2001;50:689-94.

5 Cook DB, Sackett DL, Spitzer WO. Methodologic guidelines for systematic reviews of randomized controlled trials in health care from the Potsdam consultation on meta-analysis. J Clin Epidemiol 1995;48:167-71.

6 MacKay M, Scanlan A, Olsen L, et al. Sports and recreation injury prevention strategies: systematic review and best practices. Executive summary. B.C. Injury Research and Prevention Unit \& Plan-it Safe, Children's Hospital of Eastern Ontario. 2001. www.injuryresearch.bc.ca/Publications/Reports.

7 McGrath A, Ozanne-Smith J. Heading injuries out of soccer. Monash University Accident Research Centre, 1997 September. Report No 125.

8 Jadad AR, Moore RA, Carroll D, et al. Assessing the quality of reports of randomized clinical trials: is blinding necessary? Control Clin Trials 1996;17:1-12.

9 Ekstrand J, Gillquist J. Soccer injuries and their mechanisms: a prospective study. Med Sci Sports Exerc 1983;15:267-70. 
10 Ekstrand J, Gillquist J. Prevention of sport injuries in football players. Int J Sports Med 1984;5(suppl): 140-4.

11 Caraffa A, Cerulli G, Projetti M, et al. Prevention of anterior cruciate ligament injuries in soccer: a prospective controlled study of proprioceptive training. Knee Surg Sports Traumatol Arthrosc 1996:4:19-21.

12 Lehnhard RA, Lehnhard HR, Young R, et al. Monitoring injuries on a college soccer team: the effect of strength training. J Strength Cond Res 1996; 10:1 15-19.

13 Elias SR, Roberts WO, Thorson DC. Team sports in hot weather: guidelines for modifying youth soccer. Physician and Sports Medicine 1991;19:67-78.
14 Anderson SJ, Griesemer BA, Johnson MD, et al. Injuries in youth soccer: a subject review. Pediatrics 2000;105:659-61.

15 Matser EJT, Kessels AG, Lezak MD, et al. Neuropsychological impairment in amateur soccer players. JAMA 1999;282:971.

16 Kirkendall DT, Jordan SE, Garrett WE. Heading and head injuries in soccer. Sports Med 2001;31:369-86.

17 Committee on Sports Medicine and Fitness: American Academy of Pediatrics. Injuries in youth soccer: a subject review. Pediatrics 2000;105:659-61.

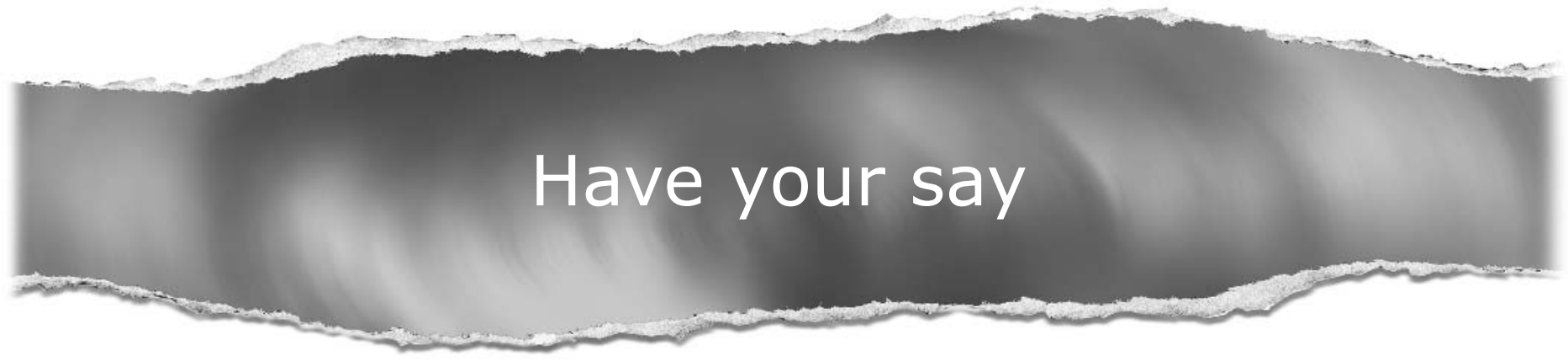

\section{eLetters}

If you wish to comment on any article published in the British Journal of Sports Medicine you can send an eLetter using the eletters link at the beginning of each article. Your response will be posted on British Journal of Sports Medicine online within a few days of receipt (subject to editorial screening).

\section{www.bjsportmed.com}

